Daimon. Revista Internacional de Filosofía, Suplemento $n^{\circ} 7$ (2018), pp. 175-189

ISSN: 1130-0507 (papel) y 1989-4651 (electrónico)

http://dx.doi.org/10.6018/daimon/334021

\title{
Cooperación y fraternidad civil
}

\author{
Cooperation and civil fraternity
}

\begin{abstract}
Resumen: La crisis en la que estamos inmersos tiene entre sus causas una profunda crisis de relaciones entre las personas. Frente a esta tendencia al desanclaje relacional de la modernidad, es posible asumir el riesgo de la confianza y la cooperación y asegurar la base de una nueva convivencia democrática, integradora y solidaria, que responda al reto de la globalización y la interdependencia. Sólo se saldrá de la crisis de relaciones desde valores basados en la solidaridad, asentada en la confianza mutua. Algunas propuestas para regenerar el sistema de valores apelan el paradigma de la fraternidad: la globalización de la solidaridad como respuesta a la crisis de la globalización.

Palabras clave cooperación, confianza pública, interdependencia, modernidad líquida, fraternidad civil.
\end{abstract}

MARÍA DOLORES GARCÍA-ARNALDOS*

\begin{abstract}
The crisis in which we are immersed is caused by a deep crisis of relationships between people. Faced with the towards relational disembedding tendency of modernity, it is possible to assume the risk of trust and cooperation and to ensure the basis of a new democratic, integrative and solidary coexistence that responds to the challenge of globalization and interdependence. The crisis of relationships will emerge only from values based on solidarity and mutual trust. Some proposals to regenerate the value system appeal to the paradigm of fraternity: the globalization of solidarity as a response to the crisis globalization.
\end{abstract}

Key words: cooperation, public trust, interdependence, liquid modernity, civil fraternity

\section{Introducción}

No es una novedad afirmar que la crisis en la que estamos inmersos es una "crisis globalizada" ya que afecta a un considerable número de países y se extiende a muchos aspectos de la vida personal, social y política de las personas y grupos que componemos la humanidad. Si nos situamos en la Unión Europea -donde se consideró prioritario poner en marcha el mercado común y la moneda única, pensando que así se edificaba una unión cimentada en

Recibido: 09/06/2018. Aceptado: 09/07/2018.

* Doctorado Interuniversitario en Lógica y Filosofia de la Ciencia por la Universidad de Santiago de Compostela. E-mail: dolores.arnaldos@rai.usc.es. Líneas de líneas de investigación: epistemología, filosofía de la lógica, filosofía social. Recientemente ha publicado: "Elizabeth Anscombe: razones y acciones" en Mª Gloria Ríos Guardiola, Ma Belén Hernández Glez., E. Esteban Bernabé (eds.), Mujeres con luz, Murcia: Editorial EDITUM (2017), pp. 89-108; y, "El problema de la justificación del conocimiento básico”, aceptado para su publicación en Revista Anales del Seminario de Historia de la Filosofia. Madrid: UCM. 
aspectos concretos de la vida de las personas y de los Estados-, vemos que tampoco escapa de dicha crisis. Tras el entusiasmo inicial, el proyecto de una Europa unida comienza a mostrar ciertas carencias. No parece suficiente la búsqueda de unidad económica.

En Europa se aspira a un proyecto que lidere también la unidad social y política que, respetando la diversidad, la haga mucho más fuerte y solidaria. Se sueña con una Europa de los Derechos Humanos, donde el centro sean las personas y su dignidad. Una Europa basada en los derechos y deberes del ciudadano, de cada ciudadano sin ninguna discriminación, en el respeto y la integridad de las personas. Esa Europa de los Derechos Humanos sería la Europa de la unidad en la diversidad. La Europa de las personas con sus propias identidades, con la pluralidad de culturas, diversidad de lenguas. Una Europa que se construya desde la democracia, que respete la identidad de pueblos y regiones y sea un instrumento eficaz para resolver los problemas sociales y económicos desde la garantía del interés general. Una Europa unida, y no uniforme, basada en la diversidad y en la plena garantía de los derechos de todos los ciudadanos. Pero, cómo se podría realizar ese proyecto.

Una de las hipótesis acerca del origen de la crisis de Europa es que surge de la crisis de las relaciones y de los valores humanistas fundacionales del proyecto europeo. Esto nos sitúa frente al significado profundo de una integración y a la cuestión de si realmente se apoya en un patrimonio compartido con raíces culturales comunes. Si falta esa base, cómo será posible superar las diferencias entre pueblos y las exigencias de cada Estado, que simplemente se yuxtaponen en lugar de avanzar en una mayor interdependencia. Se hace necesario, pues, un nuevo enfoque que vaya más allá de la ambición, la competición o el interés propio para apostar en un proyecto que conlleve ventajas mutuas, interdependencia y fraternidad:

Fraternity is in fact the forgotten principle of Modernity in Western society. When the founders of Modernity announced the new principles of the new world, liberté egalité fraternité, they said something crucial: individual freedom and social equality are not enough for building the new post-ancient régime society, because neither liberty nor equality say "bond", relationships among persons. ${ }^{1}$

Pero, ¿por qué sería la fraternidad una respuesta a la crisis globalizada?

El argumento podríamos formularlo así: la crisis en la que estamos inmersos tiene entre sus causas una profunda crisis de relaciones entre las personas. Frente al desanclaje relacional de la modernidad "líquida" la confianza que, junto con la cooperación promuevan "bienes relacionales"4, como la solidaridad o la fraternidad. Si superamos esta crisis de relaciones, asumiendo nuevos paradigmas políticos y sociales, aseguraremos la base de una nueva convivencia democrática, integradora y solidaria, que responda al reto de la globalización y la interdependencia. Es necesario, pues,

1 L. Bruni (2012), The Genesis and Ethos of the Market, Hampshire: Palgrave Macmillan, p. 206.

2 Z. Bauman (2002), Modernidad líquida, Buenos Aires: Fondo de Cultura Económica.

3 El compromiso es uno de los elementos de la fraternidad: «To be fraternal was to be bound to other people, by ties of obligation or commitment». P. Spicker (2006), Liberty, Equality, Fraternity, Bristol: The Policy Press, p. 119.

4 La categoría de "bien relacional" fue introducida en el debate teórico a finales de los ochenta y en España en los noventa, sobre todo con la publicación de M. Nussbaum (1995), La fragilidad del bien. Cfr. L. Bruni, (2008), El precio de la gratuidad, Madrid: Ciudad Nueva, p. 89. 
un nuevo modo de organizar la sociedad y, como consecuencia de ello, es necesaria una nueva forma de hacer política y de plantear una economía en función de la nueva sociedad, un nuevo modelo que debe estar basado en la solidaridad y centrado en las personas.

Algunas propuestas ${ }^{5}$ para regenerar el sistema de valores sostienen que es posible desde el paradigma de la fraternidad social. Una nueva forma de hacer economía y política basado en la fraternidad, en las relaciones de las personas y los pueblos. Aspectos esenciales del paradigma de la fraternidad son la acción colectiva, la cooperación y la ayuda mutua (o responsabilidad de ayudar a otros) ${ }^{6}$, pero también, el respeto a la dignidad de las personas, la solidaridad y la cohesión social. Esto significa que sólo se saldrá de la crisis, desde valores basados en la solidaridad, asentada en la confianza mutua, ya que, sin cooperación, sin confianza, no hay desarrollo. Si además se considera cualquier idea de destino común, el individualismo egoísta y depredador es incompatible. La solidaridad7, como la fraternidad, comparten el compromiso de ayuda mutua y para ello, se requiere cooperación.

\section{Cómo nace la cooperación}

Esto nos lleva a un lugar común, a una pregunta que hunde sus raíces en el pensamiento antiguo: cómo nace la cooperación humana, ¿nacen los sujetos naturalmente egoístas e individualistas y después la vida en común les impone sus normas sociales de cooperación o, en cambio, nace el ser humano propenso a la cooperación y es la vida en común, el oportunismo, la escasez de recursos, lo que hace que los individuos se comporten de un modo prudente, oportunista?

El libro del psicólogo evolucionista americano, Michael Tomasello, Altruisti nati, propone una solución de inspiración rousseauniana ${ }^{8}$, a partir de experimentos de economistas, basada en la tesis de que la especie humana es naturalmente altruista, pero poco a poco, se va adaptando a las normas. Tomasello busca nuevas respuestas, a partir de la observación cotidiana de niños entre el primer y el segundo año, a la cuestión acerca de si tendemos a la cooperación naturalmente o no. El resultado de los experimentos, según expone, ha demostrado que cualquier niño es naturalmente social y está dispuesto a ayudar dejando de lado su provecho personal, antes incluso de que sus padres le introduzcan en lo que llamamos "buena educación". Pero este altruismo inicialmente indiscriminado, luego se vuelve selectivo 9 .

5 Además de la obra citada anteriormente de L. Bruni (2012) en el área económica, en el ámbito de la filosofía política, por ejemplo, A. M. Baggio (2006), Il principio dimenticato. La fraternità nella riflessione politologica contemporanea, Roma: Città Nuova. En el ámbito del Derecho, una obra reciente es: A. Cosseddu (ed.), (2016), I sentieri del giurista sulle tracce della fraternità. Ordinamento a confronto, Torino: G. Giappichelli Editore.

6 P. Spicker (2006), Liberty, Equality, Fraternity, Bristol: The Policy Press, p. 120.

7 «The concepts of solidarity and fraternity share a commitment to mutual aid and social responsibility. Solidarity differs from fraternity by emphasising moral obligation, rather than cooperation, as the binding force which guides social action». P. Spicker, Ibídem, p. 130.

8 Dice Tomasello: «Qui sosterrò una tesi che in línea di massima si schiera con la visione di Rousseau, ma la integra con alcune riflessioni critiche». M. Tomasello (2010), Altruisti nati. Perché cooperiamo fin da piccoli, Bollati Boringhieri, p. 21.

9 Cfr. M. Tomasello, Ibídem, p. 52. 
Por su parte, Luigino Bruni ${ }^{10}$ está de acuerdo con Tomasello en la idea aristotélica de que el ser humano es un animal social; sin embargo, subraya que el ser humano desde su nacimiento no es ni un primate, ni el "buen salvaje" de las comunidades primitivas"1, sino que el ser humano nace ya humano. También está de acuerdo con Tomasello en que, como en todo gran debate, ambas posiciones contienen algún grado de verdad ${ }^{12}$, pero subraya especialmente que la teoría de Rousseau no excluye totalmente la de Hobbes ${ }^{13}$. Según Bruni, los niños no son egoístas que persiguen el propio interés buscando la seguridad por temor a los demás, ni tampoco nacen como el "buen salvaje" y con el tiempo se van corrompiendo conforme van interactuando en el entramado social. Descubrir en qué momento y de qué modo nace la cooperación humana comprende múltiples factores; además de la evolución de la interacción humana, uno de los factores a tener presente es la capacidad de discernimiento en esa evolución. Desde el punto de vista de Bruni, Tomasello parece estar atribuyendo al niño una capacidad de discernimiento muy elevada. Si así fuese, deberíamos resolver primero la cuestión siguiente: ¿la capacidad de mind-reading, de leer la mente del otro comienza a una edad temprana o, en cambio, la capacidad de leer las intenciones del otro madura con la vida en común?

Bruni se sitúa más bien en el marco del postulado kantiano de la "insociable sociabilidad" humana ${ }^{14}$, esto es, la consideración de que la vida en común es ambivalente. Ahora bien, de qué modo esta ambivalencia influye en la vida económica y social. La tesis de Bruni es que la "insociable sociabilidad" humana afecta directamente a un tipo de bienes denominados bienes relacionales. Dos de los bienes relacionales que se recaban de la cooperación humana -y que influyen notablemente en el ethos del mercado- son la confianza pública y la felicidad pública.

Es un tema propio de la Etica a Nicómaco la idea de que el hombre feliz tiene necesidad de amigos: «se puede ser rico en soledad, pero para ser felices es necesario ser, al menos, dos». Esta idea aristotélica, actualizada por autores como M. C. Nussbaum o A. MacIntyre según la cual la eudaimonia, la vida feliz, tiene que ver con la vida en común, -junto con la idea de la obligación de obrar conforme a la virtud con respecto a los otros (Ética a Nicómaco 1130 b) - adquiere todavía mayor relieve en la situación a la que se ha llegado en la actualidad: una situación en la que ya no somos capaces de transformar los bienes en bienestar, es decir, en la que no conseguimos estar mejor con más cosas. Nos encontramos así una parte del mundo en la que, mientras aumentan los bienes económicos tradicionales, los bienes relacionales parecen ser escasos. Hay una indigencia, en el ambiente económico, de bienes relacionales tales como la reciprocidad, la amistad, la fraternidad y el compromiso civil.

10 L. Bruni (2010), L'ethos del mercato. Un'introduzione ai fondamenti antropologici e relazionali dell'economia, Milano: Mondadori.

11 Se alude a la "sencilla y natural civilidad" de los salvajes, idea que promovió J. J. Rousseau (1750) "Discurso sobre las ciencias y las artes" en Del contrato social/Discurso sobre las ciencias/Discurso sobre el origen de la desigualdad, Madrid: Alianza Editorial, 1982.

12 Cfr. M. Tomasello, Ibidem, p. 21.

13 T. Hobbes (1651), Leviatán, Madrid: Alianza, 1989; y (1658) De homine. Trad. Ingl.: Man and citizen: Thomas Hobbes's "De homine", Hassocks: Harvester Press, 1978.

14 I. Kant (1784), Ideas para una historia universal en clave cosmopolita y otros escritos sobre Filosofia de las Historia, Madrid: Tecnos, 1987, p. 8. 
Una distinción que viene de relieve a primera vista entre bienes económicos y bienes relacionales es que, a diferencia de los bienes económicos privados que disminuyen o se pierden con su consumo, los bienes relacionales se caracterizan por ser bienes que aumentan con su uso. Es decir, si, por una parte, al consumir un bien privado, a mayor número de consumidores disminuye la utilidad particular, en el caso de los bienes relacionales, por el contrario, al aumentar los consumidores, aumenta la utilidad de todos.

La felicidad pública, según Bruni, forma parte de los bienes relacionales; es uno de los bienes, como la amistad, que nacen y mueren con la relación misma, donde lo fundamental es la reciprocidad, de ahí su fragilidad. Precisamente, la fragilidad de los bienes relacionales tiene que ver con la ambivalencia radical que encontramos en la vida en común: la vida es buena, pero vivirla es frágil -como sostiene Martha Nussbaum ${ }^{15}$-. Es decir, al no estar en nuestra mano el control de la respuesta de los otros, la amistad, la confianza, conlleva de algún modo la tragedia. Nos encontramos, pues, con una paradoja: no puedo separar la vida buena de la tragedia; ya que la vida buena, es civil; no puedo prescindir de los demás para ser feliz. Esta ambivalencia, sostiene Bruni, recorre las relaciones humanas. Siendo así que la vida buena es, a la vez, tragedia y fortuna, herida y don, la pregunta es: «¿cómo podemos estar juntos sin exterminarnos?». Según Bruni, la historia nos muestra varios intentos de soluciones a este problema.

En las culturas antiguas, las comunidades eran jerárquicas pero el punto de referencia era, en general, el grupo, el clan, la tribu; no eran comunidades fraternas, sino sagradas, las cuales convergían en un mediador sagrado. La individualidad no había emergido todavía y ante cualquier enfrentamiento, no se miraba al otro individuo en cuanto otro, entre ellos había un mediador. El centro, la mirada estaba puesta en la comunidad, en el grupo, no en el individuo. De ahí que, como una solución a la ambivalencia, Bruni defienda que «la primera inmunidad de la historia fue la comunidad misma» ${ }^{16}$.

La segunda solución la encontramos en la philia: la amistad entre iguales. Es necesario para que el mercado funcione, para que haya desarrollo, que pueda fiarme del otro. Por lo tanto, ante la cuestión «¿cómo evito que el otro me haga daño?», la solución es crear comunidades de iguales; la diversidad no se admite porque hiere. Estas son tesis que defienden posturas en la línea del comunitarismo (A. MacIntyre, M. Walzer, Ch. Taylor, M. Nussbaum) desde las cuales se afirma que se requiere una comunidad cultural necesariamente homogénea que mantenga ciertos valores. Bruni va advertir, al respecto, que el peligro siempre presente en el comunitarismo va a ser la exclusión ${ }^{17}$. Desde mi punto de vista, se podría señalar, además, que esta segunda solución es reductiva ya que la economía, el mercado, así como la política, comienzan no sólo con "lo próximo", sino

15 Martha C. Nussbaum (1986), The Fragility of Goodness: Luck and Ethics in Greek Tragedy and Philosophy. Trad. Esp.: La fragilidad del bien. Fortuna y ética en la tragedia y la filosofia griega, Madrid: Visor, 1995.

16 L. Bruni (2012), The Genesis and Ethos of the Market, Hampshire: Palgrave Macmillan, p. 34 y ss.

17 Habermas plantea la cuestión del siguiente modo: ¿cómo integrar al otro en la comunidad fundada sobre la afirmación de la igualdad de derechos y el igual respeto de cada cual, cuando la fuerza de las cosas conspira para disponer los unos de los otros? (J. Habermas (1999), La inclusión del otro. Estudios de teoría política, Barcelona: Paidós, p. 21). En La inclusión del otro, Habermas pondrá a examen las precondiciones sociales, culturales e institucionales a las que se somete el ejercicio práctico y sus límites o barreras. 
principalmente con "lo otro"18. Hay que recordar que la llegada de la Modernidad nos puso frente a una nueva paradoja; mientras, por una parte, se descubría en el otro un tú, con la consiguiente conquista de sus derechos individuales en cuanto persona; por otra parte, se fue afirmando en un proceso gradual, el enfoque individualista que dio lugar a las ideas -predominantes en la historia reciente-como las del "homo homine lupus" de Hobbes y la del homo oeconomicus solitario y solipsista de Smith. Por ello se hizo tan popular en las teorías económicas posteriores la metáfora de "Robinson Crusoe"19. Hobbes considera que los seres humanos son egoístas racionales en condición de igualdad. Al querer las mismas cosas, en ausencia de una autoridad externa, la condición de igualdad da lugar al conflicto. Sin embargo, un estado de conflicto permanente es indeseable por lo cual, es preferible pactar acuerdos y crear un tercer poder coercitivo que pueda sancionar. Dichas ideas generaron instituciones "leviatánicas", instituciones en las que un tercero -el contrato, el estado, el mercado- se encargaba de que nuestras relaciones no terminasen en conflicto o que los conflictos fuesen resueltos. Es interesante recordar que ese "tercero" es creado por el pacto, pero no es parte del pacto, ya que todos ceden sus derechos y recibe el poder absoluto. En este caso, no nos encontramos con el mediador sagrado, al contrario de lo que ocurría en las culturas antiguas; el mediador es ahora el mercado.

El planteamiento individualista de la ciencia económica a partir de la Modernidad tomó forma en lo que Martin Hollis ${ }^{20}$ llamó egoísmo filosófico, es decir, «ego entra en relación con alter sólo instrumentalmente, cuando y si necesita de él, y, por tanto, las relaciones interpersonales tienen sentido sólo como medio. Individualismo e "instrumentalidad" son, pues, dos caras de la misma moneda» ${ }^{21}$. Un camino para eliminar este individualismo de la ciencia económica se buscó a través de la matemática con la "teoría de juegos"22. Aunque significó un paso adelante ya que en el juego se parte al menos de dos -el juego más famoso es el dilema del prisionero que representa la situación en la que se hallan dos prisioneros ${ }^{23}$ por ejemplo-, actualmente se ha llegado a demostrar que la metodología de la teoría de juegos no termina de superar la teoría económica clásica "instrumental e individualista”. Es posible ser altruista e individualista a la vez y, en realidad, «son el individualismo, el egoísmo filosófico -y, (...) la lógica instrumental- la verdadera causa del fracaso de la idea de racionalidad económica y de la teoría económica basada en ella.

18 Otra es la visión, usual en la teoría económica desde la modernidad, donde se afirma desde un enfoque individualista: «En economía se parte del presupuesto de que los individuos no están unidos unos a otros por nexos indisolubles, antes de comenzar las transacciones; por tanto, es posible el ejercicio intelectual de separar ego de alter, edificando así una ciencia individualista donde se puede analizar el yo, el agente individual, independientemente de sus relaciones con el otro». L. Bruni (coord.), (2001), Economía de comunión. Por una cultura económica centrada en la persona, Madrid: Ciudad Nueva, p. 70.

19 L. Bruni, Ibídem, p. 71.

20 Cfr. M. Hollis (1998), Trust within reason, Cambridge.

21 L. Bruni (coord.), (2001), Economía de comunión. Por una cultura económica centrada en la persona, Madrid: Ciudad Nueva, p. 74.

22 Cfr. J. Von Neumann y O. Morgenstern (1944), Theory of Games and Economic Behavior, Princenton.

23 Una lectura que se hace del dilema del prisionero es que «en situaciones de interdependencia, el buscar el provecho individualista no sólo no lleva al bien común: ni siquiera lleva al bien individual» (L. Bruni, Ibidem, p. 78). Sin embargo, hay que tener en cuenta que el resultado del dilema va a depender de qué hipótesis de racionalidad se está secundando. 
Incluida la teoría de juegos» ${ }^{24}$. Por otra parte, también es posible ser solidario o actuar fraternalmente sin ser altruista:

Genovesi tells us that it is possible to maintain a fraternal attitude towards those taking part in an exchange on the market, without necessarily having to embrace altruism. The idea of fraternity or friendship, as found in Genovesi, is not a kind of behavior (like altruism, for instance) or a set of preferences (social or "other-regarding", as we shall see), but rather it is a way of perceiving and reading the market as the collective action of a team ${ }^{25}$.

Precisamente, la escuela napolitana de Genovesi (el cual trataba como sinónimos la ayuda mutua, la fraternidad y la amistad), según señala Bruni, trató de rescatar la idea de philia, de fraternidad y ponerlas en el centro de la vida en común como un tipo cualificado de socialidad ${ }^{26}$. Por su parte Bruni, retoma esta idea de fraternidad que, como veremos, le permitirá hablar del ethos del mercado. Se trata de una nueva forma de amistad o fraternidad civil:

(...) but not the fraternity that refers to shared bloodlines in family and clan ties and neither the fraternity often used by closed and discriminating communities. Rather, it is civil fraternity combined with freedom and equality. This fraternity or civil friendship on the part of the members of a community means feeling part of a common destiny, of being united by a link less exclusive and elective than intimate friendship, but which is capable of generating feelings of reciprocal sympathy, and which can and should even be expressed in ordinary market transactions ${ }^{27}$.

Bruni parte de la capacidad del ser humano de generar empatía y reciprocidad. No obstante, estamos presuponiendo, de algún modo, que la fraternidad (la libertad y la igualdad) son los principales valores o principios que pueden guiar una economía civil o una política social; pero, ¿qué sucede cuando el conflicto no nace de los principios sino de las prioridades, los deseos o las tendencias? Para muchos, tales principios no son ni siquiera un objetivo. Algunos podrían optar alternativamente por el trinomio: "trabajo", "familia", "país"28.

Nos encontramos, pues, con que el ser humano experimenta una nostalgia y un deseo del otro, pero a la vez tiene miedo de él, y este entrecruzamiento de ambivalencias es debido, sobre todo, a la escasez de recursos, de oportunidades y a las diferencias al establecer prioridades. Precisamente, "vivir en sociedad" puede causar heridas, angustia e inseguridad, provocar una crisis de relaciones y esto nos alerta de la necesidad de una reflexión pausada acerca de la realidad y de cómo las personas nos situamos en ella ${ }^{29}$.

24 L. Bruni, Ibidem, p. 79.

25 Bruni, L. (2012), The Genesis and Ethos of the Market, Hampshire: Palgrave Macmillan, p. 158.

26 Cfr. Bruni, L. Ibidem, p. 123.

27 L. Bruni (2012), The Genesis and Ethos of the Market, Hampshire: Palgrave Macmillan, p. 206.

28 Cfr. P. Spicker (2006), Liberty, Equality, Fraternity, Bristol: The Policy Press, p. 177.

29 Cfr. Z. Bauman (2005b), Identidad. Conversaciones con Benedetto Vecchi. Madrid. Losada, p. 12. 


\section{2. ¿Es posible la cooperación y la interdependencia en la Modernidad líquida?}

$\mathrm{Al}$ inicio señalamos que, si superamos la crisis de relaciones, asumiendo nuevos paradigmas políticos y sociales, aseguraremos la base de una nueva convivencia democrática, integradora y solidaria, que responda al reto de la globalización y la interdependencia. Pero, ¿qué causa la crisis de relaciones?

Zygmunt Bauman ${ }^{30}$ nos puede arrojar luz al respecto. En varias obras ${ }^{31}$ y en el marco de una relectura de la sociología moderna que Bauman ha realizado acerca del tema de la identidad, introduce la idea de una identidad líquida:

En lenguaje simple, todas estas características de los fluidos implican que los líquidos, a diferencia de los sólidos, no conservan fácilmente su forma. Los fluidos, por así decirlo, no se fijan al espacio ni se atan al tiempo. (...) La extraordinaria movilidad de los fluidos es lo que los asocia con la idea de "levedad". (...) Asociamos "levedad" o "liviandad" con movilidad e inconstancia: la práctica nos demuestra que cuanto menos cargados nos desplacemos, tanto más rápido será nuestro avance. Estas razones justifican que consideremos que la "fluidez" o la "liquidez" son metáforas adecuadas para aprehender la naturaleza de la fase actual - en muchos sentidos nueva- de la historia de la modernidad ${ }^{32}$.

Ahora bien, ¿cómo hemos llegado a la consideración de que la identidad personal es algo "líquido" y cómo afecta esto a los vínculos humanos?

En los lugares "desarrollados" del planeta, según Bauman, se está creando un escenario nuevo que plantea nuevos desafíos. En primer lugar, el paso de lo que denomina la fase "sólida" de la modernidad, a la "líquida", es decir, «a una condición en la que las formas sociales (las estructuras que limitan las elecciones individuales, las instituciones que salvaguardan la continuidad de los hábitos, los modelos de comportamiento aceptables) ya no pueden (ni se espera que puedan) mantener su forma por más tiempo, porque se descomponen y se derriten antes de que se cuente con el tiempo necesario para asumirlas $y$, una vez asumidas, ocupar el lugar que se les ha asignado» ${ }^{33}$.

Bauman va más allá de la posmodernidad cuando se refiere a la modernidad líquida. Se podría decir que la posmodernidad es la modernidad menos sus ilusiones, es un segundo desencanto, una era caracterizada por su ambivalencia insoslayable, la duda continua, el escepticismo, la contingencia moral y el pluralismo (dada la decadencia del Estado). Es una nueva sociedad en desequilibrio constante. Pero, la posmodernidad coincide con la modernidad líquida en las siguientes características: ambas se liberan de la idea de progreso; el valor del universalismo ilustrado se sustituye por el relativismo y el escepticismo. Ahora se trata de "interpretar" y "traducir" la realidad. Se anuncia el triple fin del

30 Z. Bauman (2002), Modernidad líquida, Buenos Aires: Fondo de Cultura Económica.

31 Z. Bauman (2005a), Amor líquido: Acerca de la fragilidad de los vínculos humanos, Madrid: Fondo de Cultura Económica. Z. Bauman (2005b), Identidad, Madrid: Losada. Z. Bauman (2007), Tiempos líquidos, Barcelona: Tusquets.

32 Z. Bauman (2002), Modernidad líquida, Buenos Aires: Fondo de Cultura Económica, p. 8.

33 Z. Bauman (2007), Tiempos líquidos, Barcelona: Tusquets, p. 7. 
conocimiento, del yo y de la comunidad (Rorty) ${ }^{34}$. Queda lo meramente contingente. No hay una identificación con una naturaleza humana común sino sólo proximidad con quien tiene un vocabulario semejante al nuestro o nuestras mismas prioridades. Se deja de ver la historia como un marco de realización humana. La sociedad ni se percibe como propiedad común, ni como una empresa en la que todos contribuyen. Desaparece el sujeto histórico y el ser humano deja de definirse como "ser social" por su lugar en la sociedad que antes era parte de lo que determinaba su comportamiento y su conciencia.

Ante estos cambios, todavía queda explicar las dependencias mutuas de los agentes autónomos en el espacio social y su disposición a actuar. El problema es la desconexión social, "coordinación sin integración", sumada a la falta de compromiso propias de la modernidad. Además, la noción de "espacio social" se vacía progresivamente de contenido con la llegada y aumento de los "no-lugares" 35 como aeropuertos o centros comerciales; en las ciudades de la modernidad líquida no hay lugares de encuentro.

Las consecuencias son varias, entre ellas que, en esta sociedad, los ciudadanos se convierten en "sujetos de riesgo". De hecho, una de las secuelas de la modernidad es que deja desechos como resultado, según Bauman. Uno de los productos, en efecto, de las migraciones y la globalización son los "residuos humanos". Pero todos estamos en potencial situación de riesgo, con lo cual se establecen mecanismos de autodefensa, o, como lo llama Bauman "estrategias de vida" de la posmodernidad como el culto al cuerpo ${ }^{36}$.

Por otra parte, en el análisis de cómo la modernidad pierde las referencias morales e institucionales duraderas o "fuertes" (sociedad, familia, nación), se destaca el desarraigo permanente y desmembración continua de los individuos. Las instituciones fuertes pasan a verse como instituciones "zombi", ni vivas ni muertas ${ }^{37}$. Puestas en entredicho las instituciones "fuertes" que resultaban ser el anclaje de la identidad en la modernidad sólida, es decir, anclaban la vida a unos referentes más allá del yo, ¿qué anclaje de la identidad cabe señalar en la modernidad líquida? ¿Cómo se entiende la identidad si no está "anclada" en la familia, sociedad?

Así, mientras en la modernidad sólida el problema era cómo lograr una identidad adquirida a través de la determinación social y cómo conservarla, en la modernidad liquida el problema es qué identidad se va a elegir y cómo acomodar los cambios a la variación continua de las metas. En ese sentido, se puede entender la modernidad líquida como era de la evitación, en donde se diluyen la tradición y las instituciones (se da un proceso de

34 Especialmente en R. Rorty (1989), Contingency, irony and solidarity, Cambridge: Cambridge University Press. Pero también en: R. Rorty (1991), Objectivity, relativism, and truth. Philosophical papers. Volume I, Cambridge: Cambridge University Press. Y en R. Rorty (1999), Philosophy and Social Hope. Londres: Penguin Books. Trad. esp.: El pragmatismo, Barcelona: Ariel, 2000.

35 M. Augé (1993), Los no-lugares. Espacios del anonimato. Antropología sobre la modernidad. Barcelona: Gedisa. 2009. Marc Augé acuñó el concepto "no-lugar" para referirse a los lugares de paso que no tienen importancia suficiente para ser considerados como "lugares". Un no-lugar es una habitación de hotel, un aeropuerto o un supermercado. Carece de la configuración de los espacios, es circunstancial, se define prácticamente por el pasar de individuos.

36 Hay una diferencia entre la idea de "salud" (propia de la modernidad sólida) y la de "estar en forma" (propia de la modernidad líquida). Esta tiene que ver con la idealización del cuerpo que se construye en la posmodernidad.

37 Así lo denomina U. Beck (U. Beck y E. Beck-Gernsheim. Individualización. Barcelona, Paidós, 2004; citado en Béjar 2007, 98). 
destradicionalización, de desinstitucionalización) la familia y el Estado ya no son los núcleos clave de la identidad. Hemos pasado de la era del enfrentamiento a la era de la evitación. En el ámbito afectivo, por ejemplo, esto se observa en las parejas que rompen ante el primer obstáculo, se corta en vez de tratar de reconstruir el equilibrio. Las anclas de una relación sólida se ven ahora "cargas inerciales". Frente a la inseguridad del amor se inventan estrategias como la de la flotación: la relación se establece eliminando los elementos morales, se suspende cualquier responsabilidad en relación al otro, se pide una "relación pura": nadie pide cuentas al otro por el abandono, el daño, el descuido, el desprecio o el desamor. Se deja atrás la idea de compromiso y se reemplaza por la de conexión (nueva forma de referirse a la vinculación social). Puesto que ya no hay instituciones duraderas y nos vemos obligados a un desenraizamiento, queda únicamente la identidad, pero ¿qué identidad? En la modernidad líquida, una exigencia para poder sobrevivir es la de construirse una identidad. La identidad se tiene que crear, se tienen que moldear máscaras de supervivencia. Se reemplaza la determinación heterónoma (conducta orientada por los demás y por las reglas sociales) por una auto-determinación aparentemente autónoma, pero que se acaba convirtiendo en algo compulsivo y obligatorio. Se trata de un yo en forma de tablilla donde se puede escribir, borrar y escribir de nuevo. La consecuencia de esto es que no podemos pintar el itinerario de nuestras propias vidas ya que la identidad también es algo temporal, formada por episodios cerrados, como una colección de imágenes; pero, a diferencia de la fotografía, que fija las imágenes (y pertenece a la modernidad sólida), como una cinta de video que en cualquier momento se puede borrar y grabar de nuevo. Puesto que una de las características de la modernidad líquida es la falta de finalidad, la configuración de la identidad permanecerá siempre como una labor inconclusa.

Como hemos visto, en la modernidad líquida, el individuo tiene que pasar por un proceso para poder integrarse a una sociedad cada vez más global ${ }^{38}$, pero sin identidad fija. Dadas las múltiples mutaciones que el sujeto debe enfrentar en su vida actualmente, es necesario hacerse con una identidad flexible y versátil, pero visto desde el propio sujeto solo se ve la fragilidad y el constante desgarro. Si antes, la sociedad sólida se caracterizaba por el sentido de pertenencia del individuo a los distintos estratos sociales, ahora, las identidades globales, volubles y propiamente frágiles, oscilan según la tendencia que marca el consumismo.

Otro problema es que en la sociedad líquida (al contrario que en la sólida en que se caracterizaba por el sentido de pertenencia del individuo a los distintos estratos sociales), el mismo término "sociedad" se va difuminando y se va sustituyendo por el de "red". Se reemplaza la calle como lugar de encuentro, por el mundo virtual de Internet, la sociedad por la "red", los vínculos por los "flujos". Bauman lo expresa así: «cuando encendemos el móvil, apagamos la calle».

Según Bauman, la búsqueda de la identidad es una labor ${ }^{39}$ y una responsabilidad de cada persona; se trata de la tarea de construirse a sí mismo. Las identidades, como seña-

38 No obstante, dice Bauman: «La idea de que nada en la condición humana se da de una vez por todas ni se impone sin derecho de revisión ni reforma (de que todo lo que es necesita "ser hecho" primero y que, una vez hecho, puede cambiar indefinidamente) se halla en la era moderna desde sus inicios» (Z. Bauman (2005b), Identidad, Madrid: Losada, pp. 175-176).

39 En un sentido semejante al que podemos encontrar en Arendt: «Labor es la actividad correspondiente al proceso biológico del cuerpo humano, cuyo espontáneo crecimiento, metabolismo y decadencia final están ligados a las 
lamos antes, ya no son adquiridas sino auto-constituidas. No obstante, cabe señalar que esta tarea hay que entenderla bien. Un sujeto no puede constituir su identidad sin referirse a algo distinto de sí mismo puesto que cada ser se define en relación a otro, somos seres relacionales ${ }^{40}$. Es posible, asimismo, una vuelta a las referencias sin dimitir de la responsabilidad propia, es decir, sin dimitir del ejercicio de la libertad (dar/negar consentimiento) en la constitución de nuestra identidad ${ }^{41}$. Precisamente, esta identidad inaprensible nos hace cada vez más dependientes del otro, y es ahí donde se encuentra la esperanza de crear condiciones de crecimiento en términos de humanidad, conciencia colectiva por el bien individual a partir del común. Es la apuesta de Bauman por la interdependencia. En ese sentido, Bauman identifica una "zona gris" en la que no logran entrar los mercados, zona que éstos desdeñan y que querrían extirpar de raíz del mundo que está bajo su poder. Esa zona gris es:

«(...) una comunidad, un vecindario, un círculo de amigos, compañeros de vida y de por vida: un mundo donde la solidaridad, la comprensión, el intercambio, la ayuda mutua y la compasión (todas nociones ajenas al pensamiento económico y aborrecibles para la economía práctica) dejan en suspenso o dan la espalda a las elecciones basadas en la racionalidad y la búsqueda del propio interés individual. Un mundo cuyos habitantes no son competidores ni objetos de uso y consumo, sino compañeros (que ayudan, que reciben ayuda) en el constante e interminable esfuerzo conjunto de construir una vida en común y de hacer que esa vida en común sea más fácil» ${ }^{42}$.

necesidades vitales producidas y alimentadas por la labor en el proceso de la vida. La condición humana de la labor es la misma vida» (H. Arendt (2009), La condición humana, Buenos Aires: Paidós, p. 21). «(...) la palabra 'labor', entendida como nombre, nunca designa el producto acabado, el resultado de la labor, (...)» (H. Arendt, Ibidem, p. 98).

40 Así, si se quiere destruir una identidad, se destruye cualquier relación. Uno de los proyectos más atroces de destrucción de un pueblo es descrito por un testigo directo: Primo Levi. De hecho, los así llamados "campos de aniquilación” son lugares de destrucción de la identidad: «Entonces por primera vez nos damos cuenta de que nuestra lengua no tiene palabras para expresar esta ofensa, la destrucción de un hombre. En un instante, con intuición casi profética, se nos ha revelado la realidad: hemos llegado al fondo. Más bajo no puede llegarse: una condición humana más miserable no existe, y no puede imaginarse. No tenemos nada nuestro: nos han quitado las ropas, los zapatos, hasta los cabellos; si hablamos no nos escucharán, y si nos escuchasen no nos entenderían. Nos quitarán hasta el nombre: y si queremos conservarlo deberemos encontrar en nosotros la fuerza de obrar de tal manera que, detrás del nombre, algo nuestro, algo de lo que hemos sido, permanezca» (Primo Levi, Si esto es un hombre).

41 «Pero éste era el sentido, (...): que precisamente porque el Lager es una gran máquina para convertirnos en animales, nosotros no debemos convertirnos en animales; que aun en este sitio se puede sobrevivir, y por ello se debe querer sobrevivir, para contarlo, para dar testimonio; y que para vivir es importante esforzarse por salvar al menos el esqueleto, la armazón, la forma de la civilización. Que somos esclavos, sin ningún derecho, expuestos a cualquier ataque, abocados a una muerte segura, pero que nos ha quedado una facultad y debemos defenderla con todo nuestro vigor porque es la última: la facultad de negar nuestro consentimiento. Debemos, por consiguiente, lavarnos la cara sin jabón, en el agua sucia, y secarnos con la chaqueta. Debemos dar betún a los zapatos no porque lo diga el reglamento sino por dignidad y por limpieza. Debemos andar derechos, sin arrastrar los zuecos, no ya en acatamiento de la disciplina prusiana sino para seguir vivos, para no empezar a morir» (Primo Levi, Si esto es un hombre).

42 Z. Bauman (2005a), Amor líquido: Acerca de la fragilidad de los vínculos humanos, Madrid: FCE, p. 97. 
La necesidad de solidaridad, dice Bauman, resiste y sobrevive a los embates del mercado. Es más, Bauman llega a afirmar que la solidaridad, el amor al prójimo, es condición para la supervivencia. Así, si la construcción de la identidad parecía una estrategia en la modernidad líquida para sobrevivir, con el ingrediente del amor al prójimo, «la supervivencia de un humano se transforma en la supervivencia de la humanidad en el ser humano» ${ }^{43}$.

\section{La apuesta por la confianza pública y la fraternidad civil}

Por su parte, Bruni sostiene que es posible y es deseable que sea la "zona gris" -en términos de Bauman-, la que entre en los mercados. En ese sentido argumenta que no tienen razón ni Hobbes, ni Rousseau al sostener el egoísmo, por una parte, o el altruismo, por la otra. Es necesaria otra solución al problema de la ambivalencia. Si el hombre feliz, como decíamos al inicio, necesita de la amistad, entonces la felicidad depende de la reciprocidad, que no es un mero contrato, aunque el contrato sí sea una forma de reciprocidad. La reciprocidad ${ }^{44}$ es algo más básico aún que el egoísmo o el altruismo, también en los niños.

De los estudios realizados en los últimos años, basados en observaciones a niños y adultos, de los que hay una gran literatura empírica, y de la práctica social, afirma Bruni ${ }^{45}$, se muestra que hay una norma fundamental a la que responden los seres humanos. Una norma que explica desde la vida familiar, a la cooperación dentro de las empresas, a lo que sucede en el mercado. Esta dimensión que no es ni egoísmo ni altruismo sino la capacidad que tienen las personas de cooperar por objetivos comunes, generosos o arriesgados es la reciprocidad. La reciprocidad es un comportamiento condicional por el que se es gentil (kind), cordial, generosos no hacia todos de modo indiscriminado, sino hacia sujetos de los cuales nos esperamos un comportamiento recíproco en el futuro. En cambio, no se es kind, si podemos llegar a pensar que el otro no se comportará de modo análogo. En este caso, señala Bruni, hay que destacar una dimensión importante y es que, un acto de confianza arriesgado genera o produce reciprocidad. Esto significa que la reciprocidad no es un dato que existe en nuestro $\mathrm{ADN}$, o en determinadas comunidades o tradiciones, sino que es algo que se desarrolla cuando alguien, o alguna minoría activa, es capaz de poner en movimiento comportamientos de confianza arriesgados. Dichos comportamientos pueden activar a su vez, comportamientos de reciprocidad. Bruni la denomina reciprocidad indirecta o social.

Pero, ¿qué sucede cuando se trata de convivir en sociedades en las que no es posible establecer relaciones recíprocas? Para responder, Bruni se concentra en el mercado como institución fundamental. En su libro $E l$ ethos del mercado, -entendiendo por ethos no tanto la "ética" o los comportamientos morales, sino un estilo de vida, un modo de vivir juntos- ofrece una visión amplia y sugerente sobre el funcionamiento del mercado como institución fundamental para gobernar la cuestión de las relaciones entre extraños, como lugar de encuentro de personas e instituciones y como modelo de desarrollo económico

43 Bauman, Z. Ibídem, p.107. Bauman explica la distinción entre supervivencia y amor al prójimo y a uno mismo en las páginas siguientes de un modo muy luminoso (cfr. Bauman, Ibídem, 108 y ss.).

44 Bruni analiza, por una parte, la no-reciprocidad y por qué no conseguimos cooperar según la teoría económica y por otra, describe tres formas de reciprocidad que no desarrollaremos aquí. L. Bruni (2008) El precio de la gratuidad, Madrid: Ciudad Nueva, p. 106 y ss.

45 L. Bruni (2012), The Genesis and Ethos of the Market, Hampshire: Palgrave Macmillan, p. 110 y ss. 
diverso. Si tenemos en cuenta que, solo si forman parte de instituciones justas y eficaces y si se apoyan en la confianza, en el capital social y en las virtudes cívicas de los ciudadanos, entonces los mercados construyen la sociedad civil, podemos concluir que en el mercado se pueden establecer condiciones de colaboración para alcanzar objetivos comunes. Uno de los aspectos más relevantes es que el mercado no funciona sin confianza; concretamente, en sociedad, es lo que llamamos confianza pública. Para ejemplificarlo se vale de un juego de la Teoría de Juegos ${ }^{46}$ : el juego de la confianza.

A grandes rasgos, el juego es el siguiente: una persona (A) inglesa quiere comprar a otra persona (B) norteamericana un sello de Lincoln que ha visto anunciado por internet, para cuya compra no se hace contrato por ser de valor menor. La situación es que A debe mandar previamente el dinero a B y B después realiza el envío. Para A se dan dos posibilidades: se puede fiar o se puede no fiar. Si no se fía, el resultado es $(0,0)$ : si no paga, no se hace el negocio. En el caso en que A se fíe, pueden darse dos situaciones, que B envíe el sello: resultado $(2,2)$; o que no lo envíe: resultado $(-1,2)$.

Es importante detenerse en el hecho de que en el momento en que A paga hay un incentivo para B a traicionar el negocio porque ahora está en ventaja. ¿Cuál sería, pues, el equilibrio perfecto? Si asumimos que el equilibrio es $(0,0)$, nos encontramos de nuevo en el Estado hobbesiano, lo cual significa que prevalece el miedo. Bruni quiere poner de relieve que las civilizaciones no avanzan cuando ven este tipo de juego y se bloquean. Avanzan en cambio, cuando se arriesgan y juegan ${ }^{47}$. Sin confianza no hay desarrollo. La confianza es una alianza, un proyecto colectivo, es lo que Bruni ha llamado, la felicidad pública.

Esta propuesta busca sostener que es posible una economía civil que encuentre soporte institucional en la colaboración y la asistencia mutua. Si se crean las circunstancias desde las cuales no se incentiven los comportamientos individualistas, no es necesario salir (o resguardarse en la "zona gris", según los términos de Bauman) de dicha economía de mercado. Para ello, se requiere que se respeten dos condiciones: en primer lugar, asumir que el ser humano es capaz de colaboración y de sociabilidad y que está a la espera de que se creen las condiciones que hagan posible tal actitud; tanto el mercado como la sociedad se pueden concebir, de este modo, como expresión de la reciprocidad, poniendo de relieve el valor intrínseco de las interacciones sociales. Su acción sólo es plenamente eficaz si también los demás se comportan del mismo modo, pero no condiciona su comportamiento al de los otros; en segundo lugar, considerar el mercado -u otro espacio social- no como algo que, de por sí, puede regular la complejidad de las relaciones humanas, sino que debe estar dentro de un marco institucional y cultural que sostenga y promueva las actitudes de colaboración.

A mi juicio, tanto la propuesta de Bruni como la identificación de la "zona gris" de Bauman ponen de relieve que la fraternidad no es un punto de llegada, sino el punto de partida. Hay zonas (los sí-lugares o espacios de fraternidad), a veces sólo fragmentos, que sabemos distinguir de los "no-lugares". Cuando no es así, para reconocerlos, quizás solo hace falta un acto de confianza arriesgado.

46 Bruni, L. (2012), The Genesis and Ethos of the Market, Hampshire: Palgrave Macmillan, p. 161 y ss.

47 Podemos encontrar, no obstante, el problema de que los jugadores no sean conscientes de que, en realidad, les interesa cooperar, o también que anticipen o no la reciprocidad negativa del otro jugador deteriorando la reputación, cooperación y confianza puesta en juego. 


\section{Conclusión}

Hay otro modo de considerar las relaciones entre las personas. En el espacio de las interacciones económicas, políticas y sociales es posible partir de acciones e intenciones colectivas como la confianza pública y la cooperación.

No obstante, las relaciones humanas son ambivalentes. Pero, en la vida social es posible superar una ambivalencia radical y apostar por la solidaridad. Si asumimos nuevos paradigmas políticos y sociales, como la fraternidad, aseguraremos la base de una nueva convivencia democrática, integradora y solidaria, que responda al reto de la globalización y la interdependencia.

En definitiva, podemos optar por defendernos a nosotros mismos y vivir la crisis de relaciones como un mal necesario o forjar un nuevo pacto social en donde nos comprometamos en los espacios sociales, económicos y políticos en la cooperación y asistencia mutua. El paradigma de la fraternidad civil es una apuesta por esto último: la globalización de la solidaridad como respuesta a la globalización de la crisis.

\section{Referencias}

Aristóteles. Ética a Nicómaco, Madrid: Alianza Editorial, 2001.

Arendt, H. (2009), La condición humana, Buenos Aires: Paidós.

Augé, M. (2009), Los no-lugares. Espacios del anonimato. Antropología sobre la modernidad. Barcelona: Gedisa.

Bauman, Z. (2002), Modernidad líquida, Buenos Aires: Fondo de Cultura Económica.

Bauman, Z. (2005a), Amor líquido: Acerca de la fragilidad de los vínculos humanos, Madrid: Fondo de Cultura Económica.

Bauman, Z. (2005b), Identidad, Madrid: Losada.

Bauman, Z. (2007), Tiempos líquidos, Barcelona: Tusquets.

Béjar, H. (2007), Identidades inciertas: Zymunt Bauman, Barcelona: Herder.

Bruni, L. (2012), The Genesis and Ethos of the Market, Hampshire: Palgrave Macmillan.

Bruni, L. (2010), L'ethos del mercato. Un'introduzione ai fondamenti antropologici e relazionali dell'economia, Milano: Mondadori.

Bruni, L. (2008), El precio de la gratuidad, Madrid: Ciudad Nueva.

Bruni, L. (coord.) (2001), Economía de comunión. Por una cultura económica centrada en la persona, Madrid: Ciudad Nueva.

Giddens, A. (2000), Sociología, Madrid: Alianza.

Habermas, J. (1999), La inclusión del otro. Estudios de teoría política, Barcelona: Paidós.

Hollis, M. (1998), Trust within reason, Cambridge.

Kant, I. (1784), Ideas para una historia universal en clave cosmopolita y otros escritos sobre Filosofía de las Historia, Madrid: Tecnos, 1987.

Kuhn, S. "Prisoner's Dilemma", The Stanford Encyclopedia of Philosophy (Spring 2017 Edition), Edward N. Zalta (ed.), URL = <https://plato.stanford.edu/archives/spr2017/ entries/prisoner-dilemma/>.

Levi, Primo (1976), Se questo è un uomo, Torino: Einaudi. 
Nussbaum, Martha C. (1986), The Fragility of Goodness: Luck and Ethics in Greek Tragedy and Philosophy. Trad. Esp.: La fragilidad del bien. Fortuna y ética en la tragedia y la filosofía griega, Madrid: Visor (1995).

Olson, Eric T. "Personal Identity", The Stanford Encyclopedia of Philosophy (Spring 2016 Edition), Edward N. Zalta (ed.), URL = <http://plato.stanford.edu/archives/spr2016/ entries/identity-personal/>.

Rorty, R. (1989), Contingency, irony and solidarity, Cambridge: Cambridge University Press. Spicker P. (2006), Liberty, Equality, Fraternity, Bristol: The Policy Press.

Taylor, Ch. (2006), Las fuentes del yo, Barcelona: Paidós.

Tomasello, M. (2010), Altruisti nati. Perché cooperiamo fin da piccoli, Bollati Boringhieri. 
